\title{
Using Games To Increase Active Learning
}

\author{
Jacqueline M. Ritzko, (E-mail: skr12@psu.edu), Pennsylvania State University, Hazleton Campus
} Sherry Robinson, (E-mail: jmc14@psu.edu), Pennsylvania State University, Hazleton Campus

\begin{abstract}
This paper will identify and describe two learning games that have been effectively used to spark interest and enthusiasm and to increase active learning in undergraduate business courses. Many current undergraduate college students have grown up with TV game shows, interactive video games, and the Internet as forms of entertainment and education. In comparison to these fast-paced, interactive mediums, a traditional lecture class can seem dull. The use of in-class games is one way to increase student engagement with the class and relevant material.
\end{abstract}

\section{INTRODUCTION}

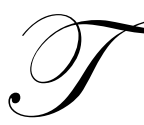

the Net Generation typically refers to the population born in the 1980's or later (Oblinger \& Oblinger, 2005). Also referred to as millennials, this population of learners poses specific challenges for educators. Ramaley and Zia (2005) stress the importance of learning environments that are social, active and learnercentered for all learners. However, they also maintain that the millennial student in particular has a strong need for engagement, social learning, and immediacy. This paper will discuss the use of two learning games as an instructional method to engage students in active learning. A study of students in three undergraduate business courses was conducted to evaluate the effectiveness and acceptance of two learning games, crossword puzzles and jeopardy, as teaching methods. The importance of this study lies in the fact that today's college students require and demand a more active and immediate learning environment. The purpose of this paper is to discuss findings based on our study of students in three undergraduate business courses as well as to discuss best-practices for the effective use of games based on our combined experiences for over 10 years.

\section{BACKGROUND}

College students are faced with many choices when it comes to time management. A common problem in today's undergraduate classrooms is that students seem to be less prepared for class and exams. Nathan (2005) confirms that this is not necessarily due to a lack of interest in learning, but a decision in time management. She reports that students assess what needs to be done to get by in a class by considering if material will be on a test or if it is needed to demonstrate proficiency in the content. The challenge that educators face then is to enable students to determine where to focus their efforts with respect to content and help them through preparation for class and exams.

In addition to time management issues, today's college students from the net generation pose specific challenges in terms of the instructional methods used. Net generation students have grown up in a fast-paced environment, entertained and taught through the use of technology. This has created an "entertain me" attitude. The purpose of this paper is not to condone or justify this attitude. Rather, it is suggested through our research that the use of learning games in the classroom can help educators meet the challenges teaching the net generation learner.

Learning theories generally point out the need for immediate feedback and student involvement for ideal learning situations (Hequet, 1995; Foreman, 2003). Learning games have been reported to provide just this type of situation. Cruickshank and Telfer (1980) point out that games provide a responsive environment where learners immediately know how they are doing. Sugar and Takacs (1999) report that games create an interactive learning experience by transforming inactive learning material into learning episodes where the learners are active players and participants. 
This type of interactive activity may be very effective in reaching the millennial student. Our goal in this study was to investigate how students perceive the use of games as a learning tool, in particular as a way of preparing and reviewing for discussions and exams. In the following section, the methodology is described, and then the results are presented and analyzed. A discussion of the findings is then presented.

\section{RESULTS AND ANALYSIS}

For this study, junior and senior business students were asked to voluntarily go to a secure online site and complete a survey in which they provided their opinions of two games used frequently in these classes, namely crossword puzzles (customized with course content) and jeopardy. Of 41 total students, 39 completed the survey for a $95 \%$ response rate. In two questions, students were asked to rate the extent to which they found each game "useful for learning material." Table 1 presents the scale used in the survey, frequency counts (percentage) and the mean results for crosswords and jeopardy.

\section{Table 1: Survey Scale And Results For "Useful For Learning Material" Questions}

\begin{tabular}{|c|c|c|}
\hline Scale & Jeopardy & Crosswords \\
\hline 1 - not at all & $0 \%$ & $15.4 \%$ \\
\hline 2 - not much & $0 \%$ & $5 \%$ \\
\hline 3 - somewhat & $2.6 \%$ & $59.0 \%$ \\
\hline 4 - quite a bit & $17.5 \%$ & $12.8 \%$ \\
\hline 5 - a lot & $79.5 \%$ & $2.6 \%$ \\
\hline Mean & 4.7692 & 2.7692 \\
\hline
\end{tabular}

Analysis of these results clearly shows that students find the jeopardy game, which was used for group inclass review before major tests, to be highly useful for learning course material. Overall, crosswords, which are an individual game that can be completed outside class, were not found to be as useful. However, further analysis indicates that the degree to which a student learns from crosswords is related to how often the student works on the puzzle. Students were also asked how often they work on (even if they don't complete) the crossword that was distributed each week. As shown in Table 2, the mean rating for usefulness of the crossword for learning material rises in conjunction with the frequency with which a student works on the puzzles. ANOVA was conducted to determine if there was a significant difference in mean ratings of the "usefulness" of both games based on the frequency of crossword completion.

Table 2: Student Completion Of Crossword Puzzles

\begin{tabular}{|l|c|c|c|}
\hline \multicolumn{1}{|c|}{ Scale } & \multicolumn{2}{c|}{ Mean rating for "useful for learning material" } \\
\hline 1- never & Frequency & Crossword & Jeopardy \\
\hline 2 - rarely & $17.9 \%$ & 1.1429 & 4.8571 \\
\hline 3 - sometimes & $20.5 \%$ & 2.8750 & 4.5000 \\
\hline 4 - usually & $38.5 \%$ & 3.000 & 4.8000 \\
\hline 5 - always & $15.4 \%$ & 3.333 & 4.8333 \\
\hline & $7.7 \%$ & 4.000 & 5.0000 \\
\hline & & $\mathrm{F}=24.245$ & $\mathrm{~F}=.875$ \\
\hline
\end{tabular}

These results indicate that mean ratings for the usefulness of crosswords varied based on the frequency of completion, but these groups were not significantly different in their evaluation of the usefulness of jeopardy. Results of correlation analysis (Table 3) confirm that higher evaluations of crossword usefulness are associated with higher completion rates. However, this is not necessarily related to an affinity for games and puzzles in general, as there was 
no statistically significant relationship between crossword completion frequencies and mean ratings for the usefulness of jeopardy.

Table 3: Correlation Results

\begin{tabular}{|l|c|c|c|}
\hline & Frequency & Crosswords & Jeopardy \\
\hline Crossword frequency & --- & .771 & .126 \\
\hline Usefulness...crosswords & $.771^{*}$ & --- & -.061 \\
\hline Usefulness...jeopardy & .126 & -.061 & -- \\
\hline * sig. .000 & \\
\hline
\end{tabular}

These results are entirely logical as students who complete crossword puzzles would naturally find them more useful for learning material than those who do not complete them. In corollary, students who do not find them useful may be less likely to complete them. As shown in Table 4, which provides representative comments from the open-ended question, "Is there a game or activity you have especially enjoyed or learned from?" the fact that crosswords are done on students' own time outside class may influence the frequency of their completion.

Table 4: Comments Regarding Games

\begin{tabular}{|l|}
\hline Crosswords: \\
\hline Crosswords were useful, however I couldn't find much time to complete them. \\
\hline Jeopardy is really helpful for preparing for the tests but I feel the crosswords are confusing, but that's just me. \\
\hline $\begin{array}{l}\text { I particularly like using jeopardy to review for our tests because it gives us a change to have the material reinforced, and } \\
\text { have a preview of what will be on the tests. }\end{array}$ \\
$\begin{array}{l}\text { I really enjoy jeopardy. It is a very nice review for all of the material. It also tells me how much I need to study for the test. } \\
\text { Also, I fell that it give student that have not had you for a teacher in any other classes an idea of what your tests are like. }\end{array}$ \\
\hline Jeopardy was very good to do because it made you remember all the material for the tests very well. \\
\hline $\begin{array}{l}\text { I like all the games, no one in particular, but I feel that it is easier to learn when we do games because it makes it a little bit } \\
\text { more fun. }\end{array}$ \\
\hline I like jeopardy a lot because it is a fun game and a good study guide all in one. \\
\hline Games in general: \\
\hline $\begin{array}{l}\text { (Game activities) gave me an opportunity to get a more in depth knowledge of the topic rather than just taking notes or } \\
\text { reading a book. }\end{array}$ \\
\hline Games are nice because they help to break up lectures with something light. \\
\hline
\end{tabular}

This question was included because the instructor used a variety of activities throughout the course. The general consensus appears to be that games in general make class more interesting, while jeopardy, in particular, is good for reviewing before tests. These were, in fact, the instructor's goals for the games. Crosswords, which are done independently, were popular with only a few students.

\section{DISCUSSION}

Our study confirms findings of Massey, Brown and Johnston (2005) in that students in both studies perceived a positive learning experience through the use of jeopardy and crossword puzzles. While this paper focused on student surveys from several business courses, it is important to note that both authors have been using learning games in their courses for over 10 years. Given what we interpret as a beneficial tool based on student survey responses, a discussion of best practices and drawbacks of currently used games based on our personal experiences of using games will be beneficial for educators wishing to implement these strategies.

Cruickshank and Telfer (1980) identify advantages as well as disadvantages to learning games. Our experience with learning games has allowed us to address many of the disadvantages mentioned in their work. They reported that teachers are relatively unfamiliar with games and thus hesitant to use them. In addition, implementation 
of games requires substantial time--more than is necessary for traditional learning environments such as lecture. While it can still be argued that more time is required to implement learning game strategies in a class setting, this cannot be the deciding factor. In designing any learning process, the first step should be identifying the instructional objectives. Based upon those objectives as well as audience analysis, decisions of appropriate methods can be made. It has been suggested through this study and others that learning games create an active learning environment that allows students to actively participate with the material and each other. The competition level that is involved in some types of learning games, such as jeopardy, stimulates an interest that may not be achievable with other teaching methods. Furthermore, the crosswords mentioned in this study were done out of class, or during "down time" such as when the instructor was passing back quizzes and assignments. Therefore, they did not require extra time. The jeopardy game was used as a review, which was built into the course schedule. The instructor needed preparation time to design the game questions, but this time could be considered an investment and the game could be used in successive courses.

Cruickshank and Telfer (1980) also state that learning games are less available than traditional teaching materials and can be expensive. In the years since their work was published, the Internet and ease of sharing and distribution of resources have negated many of their listed disadvantages. Games and simulations are becoming common forms of instruction at all levels of education. Many educators (Revere 2004; Massey et al., 2005) are sharing their findings and processes so that adoption of these techniques is easier and more effective than in previous years. The games studied in this project were created as original materials, and were not expensive. In fact, the only cost involved was the modest purchase price of the crossword software. The software used in this study was the same as described by Massey and associates (2005). However, a major modification was made to increase the "fun level" of the game as well as help the student complete the puzzle. After the original puzzle was complete, additional nonacademic words were added manually (a feature allowed by the software). This not only made the puzzles more fun (according to informal discussion with students), but provided additional help in that most words in the original completely academic puzzle intersected with only one or two other words. Again, modifying the puzzles in this way required extra time, but only had to be one once as the puzzle could be used in future courses.

Another issue with learning games is that they can result in seeming confusion and noise level, and poorlydesigned games may result in failure and/or frustration (Cruickshank \& Telfer, 1980). Indeed it seems to be a fact that the noise level in a class increases as students interact with each other in regard to the game. It has been suggested through this study and others that learning games create an active learning environment that allows students to actively participate with the material and each other, which is likely to lead to higher noise levels. However, the competition level that is involved in some types of learning games, such as jeopardy, stimulates an interest that may not be achievable with other teaching methods. Experience with in-class games has shown that an important factor in minimizing noise is minimizing "down time." Students are more likely to engage in private conversations during the times in which they are not actively involved in answering a question or otherwise participating in the game. Therefore, the key to reducing noise is decreasing the time during which only one or a few students are involved in answering a question. The issue of noise is therefore closely related to Cruickshank and Telfer's (1980) final point that the nature of many learning games limits the number of students who can be involved at one time.

As we have implemented games in our classrooms, we have identified several problems and solutions. As Hequet (1995) points out, the game should address a specific learning problem. We have used games to address several learning problems including motivating students to be prepared for class, addressing student misconceptions of content and assessing student understanding of material. We have found that students need to know the purpose of the game so that focus does not become the game itself, but rather the course content. A major factor in the learning process is the debriefing period. After games are played, we have found it important to debrief in terms of content.

As we continue to improve the format of our games and incorporate new technologies into the game process, we also include time to gather student suggestions in terms of improvements or problems of game play. For example, we have found that students are motivated by a competitive environment and in correlation, they tend to prefer rules and adherence to rules. The specific rules used in our form of jeopardy have been developed to increase fairness in the competition. First, the practice of "buzzing in" has been eliminated because there are certain to be times when a human being cannot accurately determine which team was first in indicating the desire to answer (raising of a hand, for example). Therefore, teams are assigned numbers, and each team takes a turn choosing a question, and has the first 
opportunity to answer the question. If the team is unable to answer it correctly, it goes to the next team in the rotation. Because teams are forced to choose a question, points are not deducted for an incorrect answer (until the final jeopardy round in which all teams participate simultaneously, and choose the amount they wish to wager). Due to the fact that some teams may be especially prepared or unprepared for the review, some teams may have many chances to answer extra questions, while some teams receive no additional questions. This could be seen as unfair. Therefore, the order in which teams answer is determined by random through the rolling of dice or a lottery (drawing numbers from a hat). One problem that has arisen with this orderly progression is that teams that are not likely to receive a question do not pay close attention. An accurate "buzz in" system would allow every team to have a chance to vie (speed of buzzing) to attempt to answer the question, thus reducing or even eliminating down time. Another problem is that team members may be embarrassed by repeatedly failing to answer questions. If all teams were allowed to buzz in, a team may still fail to answer any questions, but would not have the negative social consequences because they could contend that they knew the answers, but simply were not as fast as other teams in buzzing in.

In the past, we did not strictly hold to time limits for answers because some answers were longer than others. For example, if an answer included four parts, team members were allowed to discuss the answer amongst themselves in order to combine their knowledge and come up with a complete answer (no points were given for partial answers). Students, however, complained that some people were given more time. An obvious solution to this was to only use shorter answers that could be answered in a standard time period. This satisfied students' sense of fairness, but the decreased the instructor's flexibility in choosing questions.

While we have used games to provide any minimal incentives (e.g. extra points on an assignment), we feel that students are motivated primarily by the learning process itself and actively participate for the interest of the competition. Learning games can therefore be effective in increasing active learning and engagement with learning. However, in order to continue to improve the learning experience for millennial students, future research should examine the issues still remaining with the jeopardy-style game that has become so popular.

\section{CONCLUSION}

To return to the challenge that educators face with respect to helping students to determine where to focus their efforts with respect to content and class and exam preparation, student comments in this study suggest that students like the classroom games and their use as a review tool. This method supports their need to focus on relevant material in preparation for exams. Rotter (2004) also suggests using a game format to reinforce critical information while avoiding rote practice. While other teaching method may also provide this focus, the advantage of learning games is that they allow students to become actively involved with the content. The immediacy of games provides the the instructor and student with an assessment tool whereby allowing each group to be able to focus on what is necessary for teaching and learning.

Our findings support those of other educators who have implemented learning games (Revere, 2004; Massey et al., 2005). Our findings suggest that students are motivated by the use of learning games. They expressed an interest in the use of games as well as a belief that games helped in their preparation for class and exams. Based on students' comments and our research on the Net Generation, we are interested in furthering this study by incorporating more technology-related aspects to the game play, in particular the use of electronic student response systems.

\section{REFERENCES}

1. Cruickshank, D. R. \& Telfer, R. (1980). Classroom games and simulations. Theory into Practice, 19, 75-80.

2. $\quad$ Forman, D. C. (2003). Eleven common-sense learning principles. $T \& D, 57,39-46$.

3. Hequet, M. (1995). Games that teach.. Training, 32(7), 53-58.

4. Massey, A. P., Brown, S. A. \& Johnston, J. D. (2005). It's all fun and games ... Until they learn. Journal of Information Systems Education, 16, 9-14.

5. $\quad$ Nathan, R. (2005). My freshman year: What a professor learned by becoming a student. Cornell University Press: Ithaca NY. 
6. Oblinger, D. \& Oblinger, J. (2005). Introduction. In D. Oblinger \& J. Oblinger (Ed.), Educating the Net Generation. Retrieved December 10, 2005 from http://www.educause.edu/Introduction/6059.

7. Ramaley, J. \& Zia, L. (2005). The real versus the possible: Closing the gap in engagement and learning. In D. Oblinger \& J. Oblinger (Ed.), Educating the Net Generation. Retrieved December 10, 2005 from http://www.educause.edu/ TheRealVersusthePossible\%3AClosingtheGapsinEngagementandLearning/6064.

8. Revere, L. (2004). Classroom jeopardy: A winning approach for improving student assessment, performance, and satisfaction. Decision Line, 23(3), 4-6.

9. Rotter, K. (2004). Modifying "Jeopardy" games to benefit all students. TEACHING Exceptional Children, 36(3), 58-62.

10. Sugar, S., \& Takacs, G. (1999). Games that teach teams: Tale of the RAT. The Journal for Quality and Participation, 22, 54-55.

\section{NOTES}

